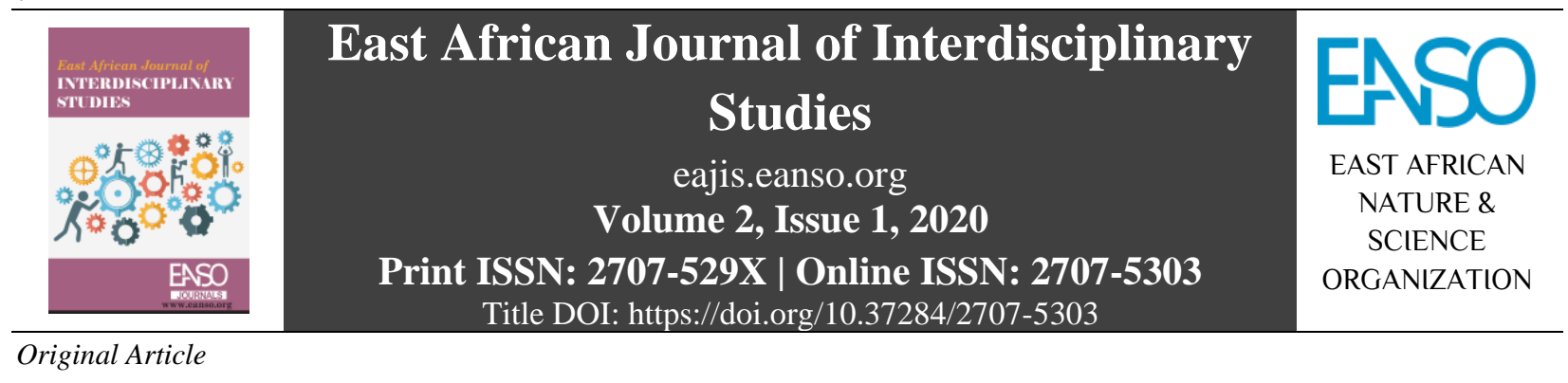

\title{
Cultural Challenges in Adherence to HIV Prevention among Youth in Kisarawe District, Tanzania
}

\section{Bertha Erasto Losioki ${ }^{1 *}$}

${ }^{1}$ Department of Education, The Mwalimu Nyerere Memorial Academy, P. O. Box 9193, Dar es Salaam, Tanzania.

* ORCID: https://orcid.org/0000-0001- 8874-2356

*Author for Correspondence Email: losiokibe@gmail.com.

Article DOI: https://doi.org/10.37284/eajis.2.1.154

\section{Date Published: ABSTRACT}

09 November 2020 Youth in Tanzania and the world at large are among the vulnerable population to HIV infection. Adherence to HIV prevention remains a

Keywords: challenge in Tanzania despite the efforts to curb the pandemic. The purpose of this study was to examine cultural practices that impede

Culture, adherence to HIV prevention among the youth. The study adopted a Youth, cross-sectional design. The respondents were selected through simple $H I V$, random sampling among secondary school students and out of school Prevention, youth aged 15-35 years in Kisarawe District Coast Region, Tanzania. Data were collected through a structured questionnaire, non-participant observation and documentary review. A total of 146 respondents were involved in the study. The study findings show that customs that encourage early marriage, values and norms that limit negotiation for safe sex and traditions that limit discussion about sexuality issues were a challenge to adherence to HIV prevention among youth. Adherence to HIV prevention and access to sexuality education and reproductive health information was found to be low among youth. The study concludes that customs encouraging early marriage, values and norms limiting negotiation for safe sexual practices, traditions that limit discussions about sexuality issues and night ceremonies significantly impede youth adherence to HIV prevention. The government and nongovernmental organisations should ensure implementation of policies and laws against traditional practices that tend to increase youth vulnerability. HIV prevention programmes targeted to youth should focus on sensitisation on harmful cultural practices and ensure the availability of comprehensive sexual education among the youth population. 
East African Journal of Interdisciplinary Studies, Volume 2, Issue 1, 2020

Article DOI: https://doi.org/10.37284/eajis.2.1.154

\section{APA CITATION}

Losioki, B. (2020). Cultural Challenges in Adherence to HIV Prevention among Youth in Kisarawe District, Tanzania. East African Journal of Interdisciplinary Studies, 2(1), 139-148. https://doi.org/10.37284/eajis.2.1.154

\section{CHICAGO CITATION}

Losioki, Bertha. 2020. "Cultural Challenges in Adherence to HIV Prevention among Youth in Kisarawe District, Tanzania". East African Journal of Interdisciplinary Studies 2 (1), 139-148. https://doi.org/10.37284/eajis.2.1.154.

\section{HARVARD CITATION}

Losioki, B. (2020) "Cultural Challenges in Adherence to HIV Prevention among Youth in Kisarawe District, Tanzania", East African Journal of Interdisciplinary Studies, 2(1), pp. 139-148. doi: 10.37284/eajis.2.1.154.

\section{IEEE CITATION}

B. Losioki, "Cultural Challenges in Adherence to HIV Prevention among Youth in Kisarawe District, Tanzania", EAJIS, vol. 2 , no. 1, pp. 139-148, Nov. 2020.

\section{MLA CITATION}

Losioki, Bertha. "Cultural Challenges in Adherence to HIV Prevention among Youth in Kisarawe District, Tanzania". East African Journal of Interdisciplinary Studies, Vol. 2, no. 1, Nov. 2020, pp. 139-148, doi:10.37284/eajis.2.1.154.

\section{INTRODUCTION}

Youth in Tanzania and the world at large are among the vulnerable population for higher risk of HIV infection. According to URT (2018), out of all new infections in 2017, over one third (43\%) occurred among young people aged 24 years and below. Youth vulnerability to HIV is due to risky behaviours they practise such as non-use of condom, having multiple sexual partners and initiation of sexual activity at an early. Adherence to HIV prevention remains a challenge in Tanzania despite the efforts to curb the pandemic. HIV prevention particularly among the youth remains critical despite the fact that knowledge about HIV transmission is high (UNAIDS, 2016; TACAIDS \& ZAC, 2018). The factors that increase youth's vulnerability to HIV are lack of adequate knowledge on HIV and AIDS prevention, inadequate access to friendly HIV and AIDS services, and unfriendly sexual and reproductive health services (URT, 2018). Hence, HIV prevention among youth continued to be a challenge. The main reasons for involvement in risky sexual activity are lack of confidence to negotiate condom use, especially by girls and inadequate information and skills for HIV prevention (UNAIDS, 2016; URT, 2017a).

Culture affects health-related behaviour and its influence on HIV preventive behaviour is powerful. A study conducted in Sudan and Yemen for example showed that both sexual and behavioural culture surrounding HIV/AIDS is a crucial aspect of HIV spread and prevention (Bashir et al., 2019). Cultural norms regarding relationships were also found to be contributing factors to a greater risk of HIV transmission. WHO (2019) show that myths and misconceptions about sexual and reproductive health services and HIV care and treatment were barriers to HIV prevention efforts targeted to adolescents in Tanzania. Parents and care providers were also found to increase misconceptions as they impose their values, cultural norms and beliefs on adolescents. Cultural values for example can affect people's feelings about risks and measures to be taken to adopt prevention strategies (O’Donohue et al., 2013). In addition, cultural factors such as traditions that encourage early marriage, negative beliefs 
about condoms due to prevailing myths and misconception, incest practices, cleansing practices as well as attendance in traditional ceremonies contribute in risky sexual encounters (Bashir et al., 2019). Early marriage for example is reinforced by cultural beliefs and it has harmful outcomes including health risks (Schaffnit et al., 2019). Hence, culture increases the possibilities for HIV infection and limit HIV prevention strategies.

The sociocultural theory explains how individuals, social and contextual issues can affect human actions and behaviour. That is, institutions and culture can influence people's thinking and behaviour (Polly et al., 2017). The theory posits that behaviours, attitudes and beliefs develop as individuals relate their views with those of other people. It also recognises both differences in individuals within a culture and differences in individuals across cultures (Mesoudi, 2016; Polly et al., 2017). In the context of this study, the theory shows that cultural factors can affect HIV prevention differently among youth in terms of sex and age. Likewise, HIV prevention strategies are adhered differently by youth. Hence, the study used this theory to show how cultural practices can limit youth ability to seek and adhere to HIV prevention measures.

Tanzania is committed to strengthening HIV prevention initiatives that aim to reduce HIV infections. A combination of prevention strategies are used and they are effective in the reduction of HIV transmission and acquisition (URT, 2018; URT, 2017b). The strategies include biomedical, behavioural and structural interventions. Biomedical interventions involve HIV testing services, condom promotion and provision and STI's treatment.
Behavioural interventions include behaviour change, communication and mobilisation and demand creation for HIV prevention services and adherence. Structural interventions targeted services for key vulnerable populations, specific interventions addressing youth, fighting stigma and discrimination (UNAIDS, 2016; URT, 2017b; URT, 2018). Combination prevention programmes aim to improve HIV prevention through empowerment, inclusion and agency of participant's particularly vulnerable populations (Brody et al., 2019). However, there is still a challenge in adherence to HIV prevention such as limited accessibility and low utilisation of condoms at the community level and inadequate sensitisation of community members including religious and traditional leaders. Moreover, there are cultural practices that encourage HIV infection such as negative beliefs about condoms, values and norms limiting discussion about sexuality issues, night ceremonies and traditions that encourage early marriage.

The study assumed that cultural practices limit the efforts intended to curb the spread of HIV infection among youth in the study area. The study, therefore, aims to examine cultural challenges in adherence to HIV prevention among youth. The study assumed that cultural practices limit adherence to HIV prevention among youth. The study objectives were first, to determine youth adherence to HIV prevention and secondly to examine cultural challenges in adherence to HIV prevention. One of the broad outcomes of MKUKUTA II (NSGRP) is the improvement of quality of life and social well-being of Tanzanians (URT, 2010; NBS, 2014). This study, therefore, is important as it addresses one among the 
strategies in goal number (3) three, which target to reduce new HIV and AIDS infections and National HIV prevalence rate. Likewise, the study will also contribute to HIV prevention efforts as emphasised in the National HIV policy (URT, 2001). Furthermore, the study will raise community awareness on the cultural practices that increase HIV infection risks among the youth.

\section{METHODOLOGY}

The study adopted a cross-sectional design as it allowed to collect data at one point in time (Crano et al., 2015). Both quantitative and qualitative data were collected. Quantitative data was collected through structured questionnaire while qualitative data were collected through document review and nonparticipant observation. The target population for the study was both secondary school students and out of school youth aged 15 - 35 years in Kisarawe. The study sample size was 146 youth. The study employed probability sampling procedures. Simple random sampling was used to select secondary school students and out of school youth aged 15-35. School registers were used to select respondents in secondary schools. Out of school youth were selected from sampled households. The study area was selected purposively due to its location and accessibility. Quantitative data were coded, processed and analysed using Statistical Package for Social Sciences (SPSS). Descriptive statistics were used to determine the frequency and percentage. Chi-square test was used to establish differences between male and female responses and the significance of the results in the studied population. Qualitative data were categorised and coded according to key themes and the objectives of the study. Data was analysed through content analysis.

\section{RESULTS AND DISCUSSIONS}

\section{Characteristics of the Respondents}

The mean age of the respondents was 23 years. This is the age at which youth are sexually active and become vulnerable to HIV infection. According to URT (2017a), more than a half of the age structure of Tanzania population is age 24 and younger and require HIV prevention and treatment to preserve the health and the future of the productive adult population. Table 1 provides the profile of the respondents.

Table 1: Characteristics of respondents $(n=146)$

\begin{tabular}{|c|c|c|c|c|}
\hline \multirow[t]{2}{*}{ Age } & \multirow[t]{2}{*}{ Average age of respondents } & \multirow{2}{*}{$\begin{array}{l}\text { mean } \\
23 \\
\end{array}$} & \multirow{2}{*}{$\begin{array}{l}\text { min } \\
15\end{array}$} & \multirow{2}{*}{$\begin{array}{l}\text { max } \\
35\end{array}$} \\
\hline & & & & \\
\hline \multirow{3}{*}{ Sex } & & $\mathbf{n}$ & $\%$ & \\
\hline & Male & 74 & 50.7 & \\
\hline & Female & 72 & 49.3 & \\
\hline \multirow[t]{3}{*}{ Education level } & Never attended school & 5 & 3.6 & \\
\hline & Primary school Education & 91 & 62 & \\
\hline & Secondary school Education and above & 50 & 34.4 & \\
\hline \multirow[t]{2}{*}{ Marital Status } & Married or living together & 63 & 43 & \\
\hline & Divorced/separated & 17 & 12 & \\
\hline
\end{tabular}




\begin{tabular}{llcc} 
& Never married & 66 & 45 \\
\hline Occupation & Petty business and farming & 95 & 65 \\
& Students & 51 & 35 \\
\hline
\end{tabular}

Furthermore, majority of the respondents involved in small businesses and farming $(65 \%)$ and others were students $(35 \%)$. Moreover, the findings show that most of the respondents were literate, with different education levels. More than half $(62 \%)$ of the respondents had primary education. In addition, there were respondents with no education $(3.6 \%)$. Education of respondents has implication in the ability to adhere to preventive measures. Other studies have shown that youth with no education and those with primary education were more vulnerable to HIV infection compared to those with secondary education. Hence HIV prevalence decrease with the increasing educational level for both male and female (URT, 2016; TACAIDS \& ZAC, 2018).

\section{Perceived HIV Prevention Strategies among Youth}

The study findings show that less than half $(43.8 \%)$ of the youth reported having used a condom the last time they engaged in sexual intercourse. In addition, among them, 25.3\% and $18.5 \%$ were male and female respectively. Table 2 shows perceived HIV prevention among youth in details $(n=146)$.

Table 2: Perceived HIV Prevention Strategies among Youth $(\mathrm{N}=146)$

\begin{tabular}{|c|c|c|c|c|c|c|}
\hline \multirow[t]{2}{*}{ HIV Prevention Strategies } & \multicolumn{2}{|c|}{ Male } & \multicolumn{2}{|c|}{ Female } & \multicolumn{2}{|c|}{ Total $=146$} \\
\hline & $\mathbf{n}$ & $\%$ & $\mathbf{n}$ & $\%$ & n & $\%$ \\
\hline Abstinence from sex & 53 & 36.3 & 59 & 40.5 & 112 & 76.8 \\
\hline Consistence use of condoms & 37 & 25.3 & 27 & 18.5 & 64 & 43.8 \\
\hline $\begin{array}{l}\text { Sexual education and information on reproductive } \\
\text { health }\end{array}$ & 23 & 15.7 & 14 & 9.5 & 37 & 25 \\
\hline Delay sexual debut & 30 & 20.6 & 61 & 41.7 & 91 & 62.3 \\
\hline $\begin{array}{l}\text { Parents/guardians communication with youth about HIV } \\
\text { prevention }\end{array}$ & 52 & 35.6 & 16 & 11 & 68 & 46.6 \\
\hline
\end{tabular}

The findings in Table 2 suggests that condom use as the preventive strategy was low among youth in the study area and female youth are vulnerable compared to male. Likewise, a population-based HIV impact assessment done in 2016-2017 indicated that the rate of condom use among youth was low. The survey indicated that $34.9 \%$ of male youth aged 15 years and older used condoms with a non- marital and non-cohabitating partner. Also, $27.3 \%$ of females of the same age used condoms with a non-marital and noncohabitating partner (URT, 2016). Based on the study findings, it can be argued that condoms as a preventive behaviour against HIV infection are low and female youth appeared to be vulnerable compared to male youth. Moreover, inconsistent condom use was also 
observed among youth and female experienced a challenge in negotiating condom use (UNAIDS, 2016).

Abstinence from sex is another HIV prevention measure examined in the study. The study wanted to establish the perceived effectiveness of abstinence method among youth. The findings show that $76.8 \%$ of the youth reported abstinence from sexual activity. However, male adhered less to abstinence (36.3\%) compared to females $(40.5 \%)$. Other studies have also indicated that youth's in Tanzania engage in premarital sex. Tanzania HIV impact survey (2018), show that $9.4 \%$ of female youth aged 15-19 years practised premarital sex, while $14.7 \%$ of male youth of the same age practised premarital sex in the year 2016/2017. In addition, $8.7 \%$ of female youth aged $20-24$ years engaged in the same behaviour. Furthermore, $13.9 \%$ of male youth of the same age practised premarital sex in the same year (TACAIDS \& ZAC, 2018). The previous findings have delineated little adherence to abstinence from sexual activity as a preventive measure for HIV infection among male youth. The present study also shows that abstinence from sexual activity was less adhered by male youth in the study area. This suggests that male youth in the study area involved in premarital sex and they were therefore vulnerable to HIV infection and other STIs.

The study findings also show that access to sexual education and reproductive health information was low. Furthermore, less than ten per cent of female $(9.5 \%)$ and only a quarter $(15.7 \%)$ of the male had reported access to such useful information. This indicates that access to counselling services including sexual education and reproductive health information is a challenge among youth in the study area. Other studies also found that youth obtain information about sexuality issues and accessibility of SRH (Sexual and Reproductive Health) service from their peers' networks (Dunor \& Urassa, 2019). Hence, the provision of counselling services is emphasised as it provides youth with relevant information and skills that help them to protect themselves against new infection (URT, 2017b).

It was further observed that there were no specific services for the provision of sexual education and reproductive health among youth in the study area. UNESCO (2018) show that sexual education equips and empowers youth by acquiring information and forming positive beliefs, values and attitudes, relationships and skills that enable youth to communicate and make their own decisions about sexuality. From this observation, it seems that the culture of silence affects communication between parents and youth in the study area.

Regarding parents' communication with youth about HIV prevention, the findings show that less than half of parents and guardians (46.6\%) talked to youth about HIV prevention. This suggests that communication and discussions on sexual issues within the family and community are not effective. Hence, it may lead to misconceptions among youth as they lack appropriate guidance. It was reported that communication is an essential element for HIV prevention as it facilitates the exchange of information, ideas or feelings and empowers people to change their behaviour (URT, 2017b). Since human learning is a social process, social interaction plays an important role in youth development, parents and 
guardians have the role to play in youth development including to guide them in adherence to HIV prevention. A study conducted among adolescents in Zambia also found that parent-child communication was not effective and parents felt improper to discuss sexuality issues with their children (Butts et al., 2018). Likewise, learning is a fundamental part of the transfer of knowledge from parents to children. Thus, the interaction with significant others plays an important role in influencing children and youth to learn in different contexts (Butts et al., 2018).

\section{Cultural Practices Limiting Adherence to HIV Prevention}

The findings show that customs encouraging early marriage $(77.9 \%)$ and youth attendance tonight ceremonies $(58.1 \%)$ were among the cultural practices that contribute to impeding HIV prevention in the study area. Table 3 shows cultural factors impeding HIV prevention $(\mathrm{n}=146)$.

\section{Table 3: Cultural Practices Impeding HIV Prevention}

\begin{tabular}{|c|c|c|c|c|c|c|c|c|c|}
\hline \multirow[t]{2}{*}{ Cultural Practices } & \multicolumn{2}{|c|}{ Male } & \multicolumn{2}{|c|}{ Female } & \multicolumn{2}{|c|}{ Total } & \multirow[b]{2}{*}{$\chi 2$} & \multirow[b]{2}{*}{ df } & \multirow[b]{2}{*}{$\mathbf{p}$} \\
\hline & $\mathbf{n}$ & $\%$ & $\mathbf{n}$ & $\%$ & $\mathbf{n}$ & $\%$ & & & \\
\hline Customs that encourage early marriage & 47 & 32.1 & 67 & 45.8 & 114 & 77.9 & 18 & 7 & $0.012 *$ \\
\hline $\begin{array}{l}\text { Values and norms that limit negotiation } \\
\text { for safe sexual practices }\end{array}$ & 39 & 26.7 & 54 & 36.9 & 93 & 63.7 & 15 & 7 & $0.035^{*}$ \\
\hline $\begin{array}{l}\text { Traditions that limit discussions about } \\
\text { sexuality issues }\end{array}$ & 44 & 30.1 & 61 & 41.7 & 105 & 71.8 & 16 & 7 & $0.025 *$ \\
\hline Cleansing practices & 30 & 20.5 & 28 & 19.1 & 58 & 39.6 & 8 & 7 & 0.309 \\
\hline Attending night ceremonies & 36 & 24.6 & 49 & 33.5 & 85 & 58.1 & 13 & 6 & $0.043 *$ \\
\hline Incest sexual practices & 32 & 22 & 42 & 28.9 & 74 & 50.9 & 10 & 7 & 0.191 \\
\hline Belief that condoms contain HIV & 35 & 23.9 & 36 & 24.6 & 71 & 48.5 & 8 & 7 & 0.309 \\
\hline
\end{tabular}

$*=$ Significant at $p<0.05$

The study findings showed further that cultural practices such as cleansing were not common in the study areas as it was reported by less than (40\%) of the respondents. Other studies have indicated that there are practices that are supported by the culture that contribute to HIV infection (Butts et al., 2018). Moreover, the National youth policy shows that harmful practices are among the major causes of HIV infection among youth. (URT, 2007). The findings also show that there were values and norms that limit negotiation for safe sex practices among youth (63.7\%). In addition, the findings showed that female youth particularly are affected by such values and norms compared to male youth. Likewise, other studies have indicated that condom use behaviour is determined by cultural aspects. In addition, condom acceptability is related to culture, values, and beliefs of a population. Therefore, culture and norms that either promote or hinder condom use may be an important factor for condom use behaviour (Adimula \& Ijere, 2019). 
The findings further show that there were traditions that limit discussions about sexuality issues among youth (71.8\%). Moreover, the situation is worse among females. These results concur with other studies which showed that culturally female are not expected to participate actively in discussions related to sexuality issues. In addition, women are conditioned to be submissive to their male partners and they involve in the sexual activity regardless of whether prevention for HIV and other STI's infection is adhered (Kemboi et al., 2019). Hence, there are cultures which discourage open discussion about sexual issues and therefore limit adherence to HIV prevention.

Furthermore, the findings obtained through chi-square test show that customs that encourage early marriage, traditions that limit discussions about sexuality issues, values and norms that limit negotiation for safe sexual practices and night ceremonies impede adherence to HIV prevention among male and female youth significantly. Moreover, these cultural practices differ significantly among male and female respondents $(p<0.05)$. This suggests that adherence to HIV prevention is still a challenge and youth, particularly female are vulnerable compared to male. Hence there are cultural practices that continue to impede HIV prevention efforts among the youth in the study area.

The study results also show further that there was no statistically significant difference $(p>$ 0.05 ) between male and female youth in adherence to cultural practices such as cleansing practices, incest sexual practices and beliefs about condoms. This suggests that some cultural aspects contribute less to impeding HIV prevention. Moreover, prevention strategies that have not taken cultural factors into consideration contributed to an increase in HIV prevalent rates (Kemboi et al., 2019; William et al., 2013). Thus, cultural factors are to be addressed and be dealt with keenly for effective HIV prevention measures.

\section{CONCLUSION AND RECOMMENDATIONS}

The purpose of this study was to examine cultural challenges in adherence to HIV prevention among the youth. Based on the findings the study concluded that customs that encourage early marriage, values and norms that limit negotiation for safe sex and traditions that limit discussion about sexuality issues were a challenge in adherence to HIV prevention among youth. In addition, adherence to HIV prevention was low among the youth and female youth adhered less to HIV prevention compared to male youth.

Based on the findings, it is recommended that effective HIV prevention programmes should involve a combination of strategies including consideration to specific culture and traditions that increase vulnerability to HIV infection. Preventive strategies and interventions should, therefore, pay attention to realities on cultural issues since individuals live in different sociocultural contexts and they are affected differently by the cultural practices prevailing in the community. Hence Interventions targeted to youth should focus on sensitisation and provision of education on harmful cultural practices. Government and Non-Governmental Organisations should ensure implementation of policies and laws enacted against traditional practices that tend to increase youth vulnerability. Moreover, the availability of 
comprehensive sexuality education is emphasised among the youth population.

\section{REFERENCES}

Adimula, A. R., \& Ijere, I. N. (2019). Psychological Impacts and Treatment of HIV/AIDS among Nigerian Women: New Perspective toward Cultural Implications and Gender Equality. Madridge Journal of AIDS, 3(1), 50-59.

Bashir, F., Ba Wazir, M., Schumann, B., \& Lindvall, K. (2019). The realities of HIV prevention. A closer look at facilitators and challenges faced by HIV prevention programmes in Sudan and Yemen. Global health action, 12(1), 1659098.

Brody, C., Sok, S., Tuot, S., Pantelic, M., Restoy, E., \& Yi, S. (2019). Do combination HIV prevention programmes result in increased empowerment, inclusion and agency to demand equal rights for marginalised populations in low-income and middle-income countries? A systematic review. BMJ global health, 4(5), e001560.

Butts, S. A., Kayukwa, A., Langlie, J., Rodriguez, V. J., Alcaide, M. L., Chitalu, N \& Jones, D. L. (2018). HIV knowledge and risk among Zambian adolescent and younger adolescent girls: challenges and solutions. Sex education, 18(1), 1-13.

Crano, W. D., Brewer, M. B., \& Lac, A. (2014). Principles and methods of social research. Routledge.

Dunor, H. \& Urassa, J. K. (2019). SchoolBased Reproductive Health Education and Teenage Pregnancy: A case of Mtwara
Region, Tanzania. Developing Country Studies, 9(1), 20-29.

Kemboi, G. J., Onkware, K., \& Ntabo, O. M. (2019). Sociocultural Factors that Perpetuate the Spread of HIV among Women and Girls in Keiyo District, Kenya. African Journal of Gender and Women Studies, 4(1), 1-6.

Mesoudi, A. (2016). Cultural evolution: Integrating psychology, evolution and culture. Current Opinion in Psychology, 7, 17-22.

National Bureau of Statistic (NBS). (2014). Tanzania National Panel Survey Report (NPS) - Wave 3, 2012 - 2013. Dar es Salaam: NBS.

O’Donohue, W. T., Benuto, L. T., \& Woodward, T. L. (Eds). (2013). Handbook of Adolescent Health Psychology. New York: Springer

Polly, D., Allman, B., Casto, A., \& Norwood, J. (2017). Chapter 12: Sociocultural Perspectives of Learning; In West, R. E. (Eds), Foundations of Learning and Instructional Design Technology. Press Books. Lidtfoundations

Schaffnit, S. B., Urassa, M., \& Lawson, D. W. (2019). "Child marriage" in context: exploring local attitudes towards early marriage in rural Tanzania. Sexual and reproductive health matters, 27(1), 93-105.

Tanzania Commission for AIDS (TCAIDS) \& Zanzibar AIDS Commission (ZAC) (2018). Tanzania HIV Impact Survey THIS 2016-2017: Final Report. Dar es Salaam: NBS \& MHCDGEC. 
UNAIDS. (2016). Prevention Gap Report. Retrieved from The Joint United Nations Programme on HIV/AIDS, http://www.unaids.org.

United Nations Educational Scientific and Cultural Organisation. (2018). International Technical Guidance on Sexuality Education; an EvidenceInformed Approach. Paris: UNESCO

United Republic of Tanzania (URT). (2001). National Policy on HIV/AIDS. Dodoma: URT.

United Republic of Tanzania (URT). (2016). Tanzania Demographic and Health Survey and Malaria Indicator Survey. Dar es Salaam: MoHCGEC, MoH, NBS, OCGS \& ICF.

United Republic of Tanzania (URT). (2018). National HIV and AIDS Response Report for Tanzania Mainland 2017. United Republic of Tanzania

United Republic of Tanzania, (2007). National Youth Development Policy. Ministry of Labour, Employment and Youth Development.

United Republic of Tanzania, (2010). National Strategy for Growth and Reduction of Poverty (NSGRP II) Ministry of Finance and Economic Affairs. Dar es Salaam: Government Printer.

URT. (2017a). Health Sector HIV and AIDS Strategic Plan. (HSHSP IV) 2017-2022. Dar es Salaam: National Aids Control Programme \& Ministry of Health Community Development Gender Elderly \& Children. Pp.7-8
URT. (2017b). National guidelines for the management of HIV and AIDS. Second Edition. Dar es Salaam: NACP \& MHCDGEC.

World Health Organisation (WHO). (2019). Assessment of Barriers to Accessing Health Services for Disadvantaged Adolescents in Tanzania. Brazzaville: WHO. 